\title{
Assessment of Routine Tests For Occult Blood in Faeces
}

\author{
G. ROSS, * M.B., B.SC., M.R.C.P. ; C. H. GRAY, † M.D., D.SC., F.R.C.P., F.R.I.C. \\ WITH THE ASSISTANCE OF S. DE SILVA, B.SC., AND JACQUELINE NEWMAN
}

Brit. med. F., 1964, 1, 1351-1354

Routine chemical methods for the detection of occult blood in faeces depend on the peroxidase-like activity of haemoglobin and its iron-containing degradation products. The clinical value of these tests was first demonstrated by Boas (1901), using a method based on the guaiacum test for blood described by van Deen (1861). Adler and Adler (1904) claimed that the colour reaction given by benzidine was better than that given by guaiacum. The benzidine test has been modified many times, and the method of Gregersen (1919) in which faeces are tested on a glass slide was widely accepted until Needham and Simpson (1952) recommended carrying out the test on filterpaper. Benzidine is no longer obtainable in the U.K. because of its carcinogenicity and has been largely replaced by orthotolidine. "Hematest" and " occultest" reagent tablets, which contain orthotolidine and a hydrogen-peroxide-generating system, have been available commercially for several years. Hematest is the less sensitive and is recommended for use with faeces ; occultest is recommended for the detection of blood in urine but may be used with faeces if the patient has been suitably dieted for a few days before specimens are collected.

The most recent addition to the range of commercially produced simplified tests for blood is the " hemastix" reagent strip, a cellulose strip, one end of which is impregnated with an organic peroxide and orthotolidine. A modified form of this strip is now marketed in the United States as a test for blood and for free haemoglobin in urine. The value of the various chemical tests for faecal occult blood has been widely debated, and the subject has been reviewed by Hughes (1952), Needham and Simpson (1952), Thornton and Illingworth (1955), and Steingold and Roberts (1961).

Most authors think that the main defect is failure to differentiate between the peroxidase activity of blood and peroxidases of dietary origin. Interpretation of results is also complicated by the possibility that faeces may contain inhibitors and perhaps accelerators of the peroxidase reaction. These difficulties and uncertainties are eliminated by the use of the ${ }^{51} \mathrm{Cr}$ method for the determination of blood in faeces, first used in man by Owen, Cooper, Grindlay, and Bollmann (1954). This permits a quantitative assessment of faecal blood loss, but the technique is not at present suitable for routine use. Although there was a reasonable correlation between the results of chemical tests for occult blood and the amount of blood lost as measured by the isotopic method, gross discrepancies were found in individual stools and were attributed to sampling errors by Bannerman (1957), Ebaugh, Clemens, Rodnan, and Peterson (1958), and Cameron (1960). The present work was undertaken because of the paucity of information on this important aspect of testing for oscult blood in faeces. The opportunity was also taken to reassess the value of some of the currently available chemical tests and to assess the value of hemastix as a test for blood in faeces.

\section{Methods}

Routine Laboratory Orthotolidine Test.-A thin smear of faeces was made on a filter-paper; two drops of $4 \%(w / v)$ orthotolidine solution were applied to the reverse side and one drop of 10 vols. hydrogen peroxide to the side of the smear.
A blue colour appearing on the reverse side of the paper within 30 seconds was read as a positive result.

Hematest Tablet Test.-A hematest reagent tablet was placed in the middle of a thin smear of faeces made on the filter-paper square provided.' One drop of distilled water, followed about 10 seconds later by a second drop, was allowed to fall on to the tablet in such a manner that some of the water ran over the smear on to the paper. A blue colour appearing on the paper within two minutes was read as a positive result.

Occultest Tablet Test.-This test was performed in exactly the same way as with hematest tablets.

Hemastix Strip Test.-The reagent strip was rapidly dipped into and immediately withdrawn from distilled water and laid on a clean surface. A small piece of faeces on the end of an orange stick was rolled firmly but without excessive pressure on the surface of the moistened impregnated tip, which was examined for a blue colour 15, 20, and 30 seconds later. The sensitivity of the test used in this way needed to be investigated. Earlier results showed a high incidence of false-positive reactions when the strip was read at 30 seconds, a reading-time recommended for use with urine; so readings were also made at 15 and 20 seconds.

Spectroscopic Test.-About $10 \mathrm{~g}$. of faeces was ground in a mortar with approximately $40 \mathrm{ml}$. of acetone and filtered. The residue was washed with acetone, transferred to another mortar, and ground with $25 \mathrm{ml}$. of $1: 2(\mathrm{v} / \mathrm{v})$ acetic acid: ethyl acetate and filtered. The filtrate was examined spectroscopically for the absorption band of haematin at $638 \mathrm{~m} \mu$. It was then divided into two portions. To the first was added half a volume of pyridine and a few drops of fresh aqueous hydrogen sulphide. After gently mixing, the solution was examined for absorption bands of pyridine-haemochromagen at 559 and 527 $\mathrm{m} \mu$. To the second portion half a volume of $10 \%(\mathrm{v} / \mathrm{v})$ hydrochloric acid and an equal volume of ether were added, and, after shaking and allowing to separate the aqueous layer was examined for absorption bands of acid porphyrin at 557 and $602 \mathrm{~m} \mu$.

Isotopic Method.-Blood ( $20 \mathrm{ml}$.) collected by venepuncture was added to $5 \mathrm{ml}$. of acid-citrate-dextrose solution. Red cells were separated by light centrifugation and gently agitated for one hour with 0.2 to $1 \mathrm{ml}$. of isotonic saline containing approximately $50 \mu \mathrm{c}$ of ${ }^{51} \mathrm{Cr}$-labelled sodium chromate (specific activity approximately $70 \mu \mathrm{c} / \mu \mathrm{g}$.). The labelled cells were washed twice and then resuspended in normal saline and reinjected intravenously into the patient, $1 \mathrm{ml}$. of the suspension being retained for subsequent use as a standard. Blood $(5 \mathrm{ml}$.) was withdrawn, for determination of radioactivity, 20 minutes after the injection of the labelled cells, and every three days subsequently. Specimens were counted in a Phillips scintillation counter, P.W. series model, incorporating a flat $1 \frac{1}{2}$-in. $(3.8-\mathrm{cm}$.) sodium iodide thallium-activated crystal. At least 3,000 counts were made on each specimen to give a counting error of less than $2 \%$. Each stool passed by patients studied by this method was collecter and weighed. Chemical tests were performed on six small

\footnotetext{
* From the Department of Chemical Pathology, King's College Hospital, London.

f From the Department of Chemical Pathology, King's College Hospital, London.
} 
samples taken from different parts of the stool. The remainder of the stool was homogenized with an appropriate amount of water in the tared container of a M.S.E. "atomix" homogenizer. The homogenate was weighed and samples of approximately $25-\mathrm{ml}$. volume were placed in a tared plastic container, weighed, and counted in the scintillation counter used with blood. The volume of blood in the stool is given by:

Total c.p.m. in sample $\times$ weight of stool c.p.m. $/ \mathrm{ml}$. blood $\times$ weight of stool aliquot

The blood sample counted was that taken two or three days before the stool was passed.

\section{Investigations}

Three series of experiments were performed. In the first, the investigations were carried out on 90 unselected specimens of faeces received for routine investigation of occult blood by the department of chemical pathology. The patients were supposed to have been on a meat- and green-vegetable-free diet, but many were out-patients and adherence to the diet could not be established with certainty. Dependent on subsequent clinical and radiological findings, the 41 patients who had produced these stools were classified into two groups consisting of 23 likely to be bleeding (group A) and 18 unlikely to be bleeding (group B). In some cases several stools from the same patient were examined.

The second series of investigations were performed on 18 patients with iron-deficiency anaemia secondary to proved ulcerative lesions of the alimentary tract (group C) and 12 healthy volunteers, six of whom (group D) were given a meatand green-vegetable-free diet for four days before the stools were collected ; the other six (group E) were investigated while receiving a normal mixed diet. One stool was obtained from each subject and samples taken from different parts of each stool were tested.

The third series of investigations consisted of a comparison of the isotopic and the chemical methods. Of the 10 patients (group F) studied, nine were admitted to hospital because of haematemesis and/or melaena ; the tenth was receiving large doses of aspirin for the treatment of acute rheumatoid arthritis. Each of the 57 stools examined was divided into six portions for the purpose of chemical testing to study variations in the distribution of peroxidase-like activity.

All faecal specimens were tested by the routine orthotolidine test (subsequently referred to as the routine test), hemastix strips, occultest tablets, hematest tablets, and in some cases by spectroscopy. The hemastix strips were read at 15, 20, and 30 seconds and will subsequently be referred to as $15^{\prime \prime}$ hemastix, $20^{\prime \prime}$ hemastix, and $30^{\prime \prime}$ hemastix.

\section{Results}

\section{Relative Sensitivities of the Chemical Tests}

The results of the first and second series of investigations are summarized in Table I, from which the relative sensitivity of the individual tests may be assessed on the basis of the proportion of positive results obtained with the specimens of faeces from the 41 unselected cases of groups $A$ and $B$ and the 30 selected subjects of groups C, D, and E. Assessment of results in this way only ranks the different tests in order of sensitivity, and, in the absence of an accepted standard reference test or information on the amount of blood in the stools, gives no indication of their diagnostic utility. A test which gives positive results with $100 \%$ of specimens irrespective of the clinical condition of the subjects from which they were obtained would be highly sensitive but quite useless in clinical practice. Considering the results as a whole, the most sensitive tests were the routine test $(77 \%$ positive reactions) and occultest $(73 \%$ positive reactions) and the least sensitive were the $15^{\prime \prime}$ hemastix ( $52 \%$ positive reactions) and hematest ( $51 \%$ positive reactions). Increasing the reading-time greatly heightened the sensitivity of the hemastix strip test.

TABle I.-Proportion of Faecal Specimens from Unselected (Groups A and $B$ ) and Selected (Groups C-E) Subjects Giving Positive Results with the Different Chemical Tests for Occult Blood

\begin{tabular}{|c|c|c|c|c|c|c|c|c|c|c|c|c|c|}
\hline \multicolumn{2}{|c|}{ Group : } & \multicolumn{2}{|c|}{ A } & \multicolumn{2}{|c|}{ B } & \multicolumn{2}{|c|}{ C } & \multicolumn{2}{|c|}{ D } & \multicolumn{2}{|c|}{ E } & \multicolumn{2}{|c|}{ Total } \\
\hline \multirow[t]{2}{*}{$\begin{array}{l}\text { Subjects } \\
\text { Specimens }\end{array}$} & \multirow[t]{2}{*}{$\because}$. & \multicolumn{2}{|c|}{$\begin{array}{l}23 \\
49\end{array}$} & \multicolumn{2}{|c|}{$\begin{array}{l}18 \\
41\end{array}$} & \multicolumn{2}{|c|}{$\begin{array}{r}18 \\
108\end{array}$} & \multicolumn{2}{|c|}{$\begin{array}{r}6 \\
36\end{array}$} & \multicolumn{2}{|c|}{$\begin{array}{r}6 \\
36\end{array}$} & \multicolumn{2}{|c|}{$\begin{array}{r}71 \\
270\end{array}$} \\
\hline & & $\mathrm{N}$ & $\%$ & $\mathbf{N}$ & $\%$ & $\mathrm{~N}$ & $\%$ & $\mathrm{~N}$ & $\%$ & $\mathrm{~N}$ & $\%$ & $\mathrm{~N}$ & $\%$ \\
\hline $\begin{array}{l}\text { Hematest } \\
15^{\prime \prime} \text { hemastix } \\
20^{\prime \prime} \quad, \\
30^{\prime \prime} \text { "” } \\
\text { Occultest } \\
\text { Routine .. }\end{array}$ & $\begin{array}{l}. \\
\because \\
\because\end{array}$ & $\begin{array}{l}22 \\
21 \\
28 \\
34 \\
44 \\
44\end{array}$ & $\begin{array}{l}45 \\
43 \\
57 \\
69 \\
90 \\
90\end{array}$ & $\begin{array}{l}19 \\
11 \\
17 \\
23 \\
35 \\
39\end{array}$ & $\begin{array}{l}46 \\
27 \\
42 \\
56 \\
85 \\
95\end{array}$ & $\begin{array}{r}92 \\
93 \\
102 \\
105 \\
98 \\
105\end{array}$ & $\begin{array}{l}85 \\
86 \\
94 \\
97 \\
91 \\
97\end{array}$ & $\begin{array}{r}1 \\
3 \\
5 \\
10 \\
9 \\
8\end{array}$ & $\begin{array}{r}3 \\
8 \\
14 \\
28 \\
25 \\
22\end{array}$ & $\begin{array}{r}3 \\
13 \\
15 \\
29 \\
12 \\
15\end{array}$ & $\begin{array}{r}8 \\
36 \\
42 \\
80 \\
33 \\
42\end{array}$ & $\begin{array}{l}137 \\
141 \\
167 \\
201 \\
198 \\
209\end{array}$ & $\begin{array}{l}51 \\
52 \\
62 \\
74 \\
73 \\
77\end{array}$ \\
\hline
\end{tabular}

Group $\mathrm{A}=$ Patients likely to be bleeding. Group $\mathrm{B}=$ Patients unlikely to be bleeding. Group $\mathrm{C}=$ Anaemic patients with lesion of alimentary tract. Group $\mathrm{D}=$ subjects on unrestricted mixed diet.

$\mathrm{N}=$ Number of positive reactions.

From the results with group $\mathrm{C}$-that is, patients with a known lesion of the alimentary tract-it would appear that all tests are equally sensitive, giving positive results in from $85 \%$ to $95 \%$ of the stools. However, with group B, the patients unlikely to be bleeding, the same order of sensitivity is observed as when all the results are considered together. The routine test and occultest gave $95 \%$ and $85 \%$ positive results, while $15^{\prime \prime}$ hemastix and hematest gave $27 \%$ and $46 \%$ positive results only. In group $\mathrm{A}$, the patients likely to be bleeding, however, $90 \%$ of the results were positive with both the routine test and the occultest, and even the less sensitive $15^{\prime \prime}$ hemastix and hematest gave $43 \%$ and $45 \%$ positive results respectively. Thus the percentages of positive results for all the chemical tests studied are almost as high in patients unlikely to be bleeding as in those likely to be bleeding.

\section{Effect of Diet}

Table I also shows the results obtained with the healthy volunteers. The number of positive reactions, irrespective of the test used, was greater with the stools of the undieted subjects (group E) than with those who had undergone dietary preparation (group D). The high proportion of stool samples in the dieted subjects giving positive results-routine test (22\%), 30" hemastix $(28 \%)$, and occultest $(25 \%)$-is disturbing, and the potential advantage of the hematest in giving only $8 \%$ of positive reactions is outweighed by the relative insensitivity of the test to amounts of blood which are probably of clinical importance and which are readily detected by the other tests (see above).

\section{Comparison of Chemical and Isotope Methods}

The third series of experiments permit a more realistic assessment of the clinical value of the tests. The Chart shows the relation between the amount of faecal blood loss as measured by the isotope method and the percentage of positive results obtained with the different chemical tests for occult blood. Nearly all the stools were tested by each chemical method and each percentage shown is based on 50 or more tests. The Chart shows that hematest, occultest, and the routine test are unsatisfactory. With hematest positive results were given by $20 \%$ of stools containing less than $2 \mathrm{ml}$. of blood (to be referred to as "little blood"), but only $60 \%$ of stools containing $20 \mathrm{ml}$. of blood or more (" much blood") gave positive results. Hematest seems to give erratic results, but this is because the number of subjects investigated was only half that investigated with the other tests. Occultest and the routine test are about equally sensitive but barely distinguished between stools containing little blood and those with much blood. Both tests gave nearly 
$100 \%$ positive results with stools containing much blood and about $75 \%$ positive results with those with little blood.
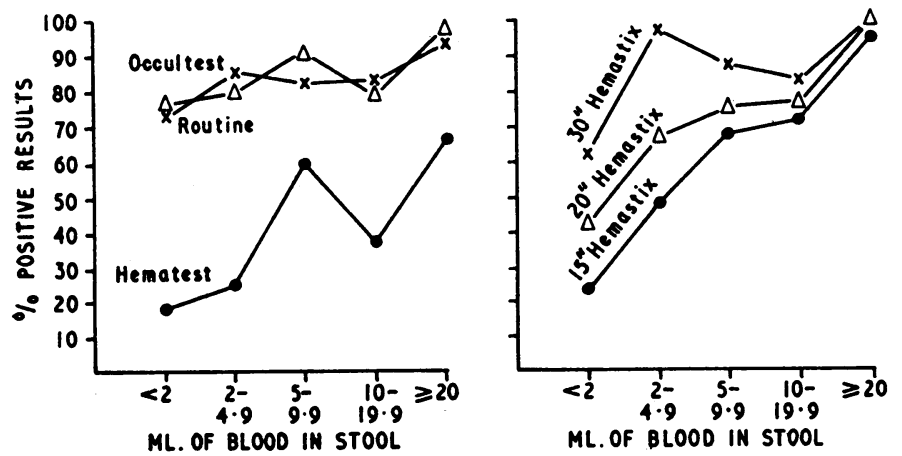

Relation between results of chemical tests for occult blood and daily quantity of blood in stool.

The results with hemastix suggest that this is more satisfactory in that there is greater difference between the percentage of positive results given by small amounts than that given by large amounts of blood (see Chart). However, when read at 30 seconds $100 \%$ positive results were obtained with stools containing much blood, but over $60 \%$ positive results were obtained with those with little blood. When read at 15 seconds the corresponding figures were $90 \%$ and $20 \%$, showing that the test used in this way is insufficiently sensitive.

A better discrimination was provided by $20^{\prime \prime}$ hemastix between stools containing a little and those containing much blood, although positive results were still obtained with $40 \%$ of the former. It must, however, be appreciated that, because of the time over which these investigations were performed, it was not practicable for the patients in this series to be put on a meat- and green-vegetable-free diet, although a number of them were on a typical gastric diet. This could account for the relatively high incidence of positive results given for stools containing less than $2 \mathrm{ml}$. of blood. Moreover, the bulk of the stool must play a part in interfering with any possible correlation between the results of the chemical tests and those given by the isotope techniques. The latter measured the amount of blood in the 24-hour stool. If there was uniform distribution of the blood throughout the stool a bulky stool weighing, say, $200 \mathrm{~g}$. would dilute the blood to a fifth of the concentration that would be achieved in a stool weighing only $40 \mathrm{~g}$.

Assuming (and this will introduce only a small error) that any 24-hour blood loss under $2 \mathrm{ml}$. means there is no pathological bleeding, then the results of the third series could be expressed as in Table II, which shows that in undieted patients none of the chemical tests have much value, for even with the less-sensitive hematest and $15^{\prime \prime}$ hemastix $20 \%$ of stools with no pathological bleeding can give positive results, and with the more sensitive routine, occultest, or $30^{\prime \prime}$ hemastix falsenegative results may be obtained in $12 \%$ to $19 \%$ of stools which contain pathological amounts of blood.

\begin{tabular}{|c|c|c|c|c|}
\hline & & & $\begin{array}{c}\% \text { False-positive Results } \\
\text { when there is No } \\
\text { Pathological Bleeding }\end{array}$ & $\begin{array}{c}\% \text { False-negative Results } \\
\text { when there is } \\
\text { Pathological Bleeding }\end{array}$ \\
\hline $\begin{array}{l}\text { Hematest } \\
15^{\prime \prime} \text { hemastix } \\
20^{\prime \prime} \quad, \\
30^{\prime \prime}, \\
\text { Occultest } \\
\text { Routine .. }\end{array}$ & $\begin{array}{l}\cdots \\
\cdots\end{array}$ & $\begin{array}{l}\ldots \\
\ldots \\
\cdots \\
\cdots\end{array}$ & $\begin{array}{l}19 \\
23 \\
42 \\
62 \\
75 \\
77\end{array}$ & $\begin{array}{l}49 \\
29 \\
22 \\
19 \\
13 \\
12\end{array}$ \\
\hline
\end{tabular}

\section{Sample Errors}

Table III shows the number of stools in the third series of experiments which gave various proportions of positive results with the various tests. Concordant results were obtained in all six samples in only $76 \%$ to $85 \%$ of the stools. There was sample variation in $15 \%$ to $24 \%$-that is, about one stool in five may be expected to show some discrepancy if six samples are tested. The results were equivocal in about half of these, showing sample variation.

TABLE III.-Sample Variation in Chemical Tests for Occult Blood

\begin{tabular}{|c|c|c|c|c|c|c|c|c|c|c|}
\hline & \multirow{2}{*}{$\begin{array}{l}\text { No. of } \\
\text { Stools } \\
\text { Tested }\end{array}$} & \multicolumn{7}{|c|}{$\begin{array}{l}\text { No. of Stools with following } \\
\text { Proportion of Positive Results }\end{array}$} & \multirow{2}{*}{$\begin{array}{c}\text { Percentage } \\
\text { of Tests } \\
\text { in which } \\
\text { All Samples } \\
\text { gave } \\
\text { Concordant } \\
\text { Results }\end{array}$} & \multirow{2}{*}{$\begin{array}{c}\text { Percentage } \\
\text { of } \\
\text { Tests } \\
\text { giving } \\
\text { Equivocal } \\
\text { Results* }\end{array}$} \\
\hline & & $6 / 6$ & $5 / 6$ & $4 / 6$ & $3 / 6$ & $2 / 6$ & $1 / 6$ & $0 / 6$ & & \\
\hline $\begin{array}{l}\text { Hematest . } \\
15^{\prime \prime} \text { hemastix } \\
20^{\prime \prime} \\
30^{\prime \prime} \\
\text { Occultest } \\
\text { Routine .. }\end{array}$ & $\begin{array}{l}29 \\
55 \\
55 \\
53 \\
49 \\
49\end{array}$ & $\begin{array}{l}11 \\
29 \\
35 \\
40 \\
35 \\
37\end{array}$ & $\begin{array}{l}-1 \\
1 \\
2 \\
5 \\
3\end{array}$ & $\begin{array}{l}1 \\
1 \\
1 \\
1 \\
2 \\
3\end{array}$ & $\begin{array}{l}1 \\
3 \\
3 \\
1 \\
1\end{array}$ & $\begin{array}{l}1 \\
1 \\
3 \\
2 \\
2 \\
1\end{array}$ & $\begin{array}{l}2 \\
7 \\
5 \\
\\
2\end{array}$ & $\begin{array}{r}13 \\
13 \\
10 \\
5 \\
4 \\
2\end{array}$ & $\begin{array}{l}83 \\
76 \\
82 \\
85 \\
80 \\
80\end{array}$ & $\begin{array}{r}10 \\
9 \\
7 \\
11 \\
10 \\
10\end{array}$ \\
\hline
\end{tabular}

* For example, positive results in 2, 3, or 4 out of 6 samples; positive results in 1 or 5 out of 6 samples are not regarded as equivocal although not concordant.

\section{Spectroscopic Test}

The results of the spectroscopic tests will not be reported in detail. In every case the sensitivity in detecting haematin was even lower than that of the hematest and 15" hemastix. However, the spectroscopic test is sensitive for the detection of porphyrin degradation products of haemoglobin which do not give a peroxidase-like action. It is therefore particularly essential for patients to be on a proper meat- and green-vegetablefree diet, under which circumstances it is very useful as a supplementary test since occasionally stools may be encountered containing much porphyrin but insufficient haematin to give a chemical test.

\section{Discussion}

The more sensitive tests for occult blood in faeces, including the routine orthotolidine test, the $30^{\prime \prime}$ hemastix strip test, and the occultest tablet test, give an unacceptably high incidence of positive reactions with the stools of normal subjects taking an unrestricted mixed diet and with those of patients losing less than $2 \mathrm{ml}$. of blood daily, as shown by the radio-chromiumlabelled red-cell technique. When these chemical tests are used it is essential to prepare the patient for a few days with a meat- and green-vegetable-free diet, but even then false positives will still occur. The less sensitive tests such as the hematest tablet test and the $15^{\prime \prime}$ hemastix strip test gave fewer positive results with the stools of normal persons not subject to dietary restriction, but comparison with the results obtained with the isotope technique showed that they are not sensitive enough to detect clinically significant faecal blood losses with any certainty. These results support the conclusion of Illingworth (1963), who advises that the hematest tablet test is insufficiently sensitive and that, because of the high incidence of positive results obtained with the stools of undieted normal subjects, tests for faecal occult blood with occultest tablets should be carried out only after dietary preparation.

The sensitivity of the orthotolidine test can be altered by varying the concentrations of orthotolidine used. The sensitivity found in the present series of investigations refers only to the conditions and the concentration described in the methods section. There is no reason, however, to suppose that if the sensitivity of the orthotolidine test was reduced by lowering the concentration of orthotolidine, the results would be any different from those given by the less sensitive tests studied in the present investigations.

Surprisingly little attention has been paid to the distribution of peroxidase-like activity in the stools of normal subjects and of patients with ulcerative lesions of the alimentary tract. It is customary to test a single small piece of faeces and to assume 
that the sample is representative of the whole stool. The assumption that stools are homogeneous is obviously unwarranted, as has been amply demonstrated by this study. Moreover, after the ingestion of charcoal or carmine it is not infrequently found that only part of a stool is coloured by the marker. Presumably the same uneven distribution can occur with haemoglobin breakdown products, particularly when bleeding started and ceased abruptly. The investigations were not designed to elucidate the number of samples which should be tested to minimize the sampling error. Nevertheless, with all the other inaccuracies of chemical tests and the unpleasantness of working with fresh stools the results of the present investigation show that there may be no need to examine more than, say, three different parts of the same stool. If these do not agree, further samples should be examined. However, samples giving equivocal results were not the same for each test, and there is need for further investigation of the extent to which inhibitors and perhaps accelerators interfere with the chemical tests for occult blood.

In the investigation of a patient with suspected disease of the alimentary tract no value can be attached to the results of any of the chemical tests for occult blood alone, since the most sensitive will sometimes give a negative result in the presence of considerable bleeding and the least sensitive will sometimes give a positive result in a healthy patient. Greatest reliance should therefore be placed on the combined results of clinical, radiological, and endoscopic examinations. If, however, these are equivocal, a positive result from the use of the less sensitive tests, such as hematest or $15^{\prime \prime}$ hemastix, suggests the presence of a lesion, but $20 \%$ of stools not containing clinically significant amounts of blood can give false-positive reactions. A negative result by a sensitive tesi, such as occultest or $30^{\prime \prime}$ hemastix, suggests no such lesion, but $10 \%$ to $20 \%$ of stools containing significant amounts of blood can give false-negative reactions.

If the results of chemical tests for occult blood were regarded as clinical signs to be interpreted along with all the other clinical evidence which in disease can be variable, inconstant, and liable to biological variation, then two tests might be used, one of low sensitivity to detect significant amounts of blood in stools, and the other of high sensitivity to distinguish stools containing negligible amounts of blood. Rather than use two different tests, hemastix might be read at 15 seconds and 30 seconds. However, it must be appreciated that there is a one-in-five chance that the result may be misleading, and it is questionable whether in these circumstances the chemical tests for occult blood should be retained in modern medicine.

\section{Summary}

The relative sensitivivty of an orthotolidine test, two tablet tests, and a strip test for occult blood in faces has been investigated.

In a separate series of investigations the results obtained with these tests have been compared with the amount of blood loss as estimated by an isotope method.

No value can be attached to the results of any of the chemical tests alone.

When equivocal results are obtained from clinical, radiological, and endoscopic examinations two tests might be used A positive result using a relatively insensitive test would suggest bleeding; and a negative result with a more sensitive test would suggest absence of bleeding. However, false-positive results with the former and false-negative results with the latter are common.

We acknowledge with gratitude the help with the radioactivity measurements given us by Dr. K. G. Leach, of the department of physics, King's College Hospital, and also that given by the nursing staff in helping so ably with the collection of specimens. We are particularly grateful to the Miles Ames Research Laboratories for a grant to provide for assistance by $S$. de Silva and to meet other incidental expenses. Dr. Geoffrey Walker, of the Miles Ames Research Laboratories, gave us much help in supplying reagents and giving us valuable advice and criticism. Mr. M. P. Curwen, of the department of medical statistics, St. Bartholomew's Hospital, was particularly helpful in his suggestions for presenting the results.

\section{REFERENCES}

Adler, O., and Adler, R. (1904). Hoppe-Seylers Z. physiol. Chem., 41, 59.

Bannerman, R. M. (1957). Brit. med. 7., 2, 1032.

Boas, I. (1901). Disch. med. Wschr., 27, 315

Cameron, A. D. (1960). Gut, 1, 177.

Ebaugh, F. G., Clemens, T., Rodnan, G., and Peterson, R. E. (1958). Amer. F. Med., 25, 169.

Gregersen, J. P. (1919). Arch. Verdau-Kr., 25, 169.

Hughes, A. (1952). Brit. med. F., 2, 970.

Illingworth, D. G. (1963). M.D. Thesis, Edinburgh University.

Needham, C. D., and Simpson, R. G. (1952). Quart. F. Med., 21, 123.

Owen, C. A., Cooper, M., Grindlay, J. H., and Bollmann, J. L. (1954). Surg. Forum, 5, 663.

Steingold, L., and Roberts, A. A. (1961). Gut, 2, 75.

Thornton, G. H. M., and Illingworth, D. G. (1955). Gastroenterology, 28, 593.

van Deen (1861). Arch. holländ. Beitr. Nat. Heilk., 3, 227.

\title{
Spinal-cord Compression in the Malignant Lymphomas
}

\author{
R. A. IRVINE,* M.B., M.R.C.P. ; W. B. ROBERTSON, $\dagger$ M.D., B.SC.
}

Brit. med. F., 1964, 1, 1354-1356

Compression of the spinal cord complicating malignant lymphomas is not unknown and several reports in the literature attest to this (Davison and Michaels, 1930 ; Browder and de Veer, 1939 ; Verda, 1944). In most cases, however, the cord symptoms become evident late in the disease and are not the primary complaint or disability which brings the patient to hospital. Rosenberg et al. (1961) reviewed some 1,269 cases, of which $35(2.7 \%)$ had cord lesions but only two presented with cord involvement as the initial complaint.

For the purpose of this paper the term "lymphoma" is used to include Hodgkin's disease, reticulum-cell sarcoma, lymphosarcoma, and lymphatic leukaemia. It does not include mye- loma or myelogenous or monocytic leukaemia. Three cases of cord compression from this cause, in which neurological symptoms were the major complaint, are presented. A fourth case, probably caused by ectopic bone-marrow, is also reviewed because of its interest and because of the difficulty that arose in differentiating histologically the atypical marrow from lymphoma. These cases are also reported because of the rapidity with which the cord symptoms in two of them regressed under treatment; in the third partial recovery has been maintained for almost five years.

* Lecturer in Medicine, University of the West Indies, Jamaica.

+ Senior Lecturer in Pathology, University of the West Indies, Jamaica. 